\title{
The Effects of the 1918-1919 Influenza Pandemic on Infant and Child Health in Derbyshire
}

\begin{abstract}
ALICE REID*
In early 1919 my father, not yet demobilized, came on one of his regular, probably irregular, furloughs to Carisbrook Street to find both my mother and sister dead. The Spanish Influenza pandemic had struck Harpurhey. There was no doubt of the existence of a God: only the supreme being could contrive so brilliant an afterpiece to four years of unprecedented suffering and devastation. I apparently, was chuckling in my cot while my mother and sister lay dead on a bed in the same room. ${ }^{1}$

Towards the end of the First World War, the world was gripped by the ravages of a pandemic of influenza. The disease spread rapidly across the globe with an alarming lack of discrimination as to who it attacked and a tendency to pneumonic complications-causing massive relative increases in mortality in young adults. In the 1920s it was estimated that, between the spring of 1918 and the early summer of 1919, the disease had affected 200 to 700 million people and killed between 10 and 21 million. ${ }^{2}$ In 1991 David Patterson and Gerald Pyle increased the estimates to between 24.7 and 39.3 million, but Ian Mills uncovered a death toll of over 21 million in India alone and more recent revisions have raised probable global influenza mortality to between 50 and 100 million. ${ }^{3}$ Even the conservative estimates put the death toll from influenza at over twice that produced by the First World War and it is generally accepted to be far higher. Yet while the war has been held responsible for the creation of a "lost generation", the 'flu was rapidly relegated to obscurity. The experience of the war and its consequences in terms of not only mortality but also social and economic re-organization (and, in the UK at least, the arrival of the Armistice during the most virulent period of the epidemic ${ }^{4}$ ) must have altered the public perspective and diminished the memory of the influenza epidemic. ${ }^{5}$ Although the widespread sickness

(C) Alice Reid 2005

*Alice Reid, PhD, Cambridge Group for the History of Population and Social Structure, Department of Geography, Sir William Hardy Building, Cambridge CB2 3EN.

\footnotetext{
${ }^{1}$ Anthony Burgess, Little Wilson and Big God: being the first part of the confessions of Anthony Burgess, London, Heinemann, 1987, p. 18. I would like to thank Niall Johnson for drawing my attention to this passage.

${ }^{2}$ Geddes Smith, Plague on us, London, Oxford University Press, 1941; Fred R van Hartesveldt (ed.), The 1918-1919 pandemic of influenza: the urban impact in the western world, Lampeter, Edwin Mellen Press, 1992, p. 1.

${ }^{3}$ David K Patterson and Gerald F Pyle, 'The geography and mortality of the 1918 influenza pandemic', Bull. Hist. Med., 1991, 65: 4-21, p. 19;
}

I D Mills, '1918-1919 influenza pandemic: the Indian experience', Ind. Econ. soc. Hist. Rev., 1986, 23: 1-40; Niall Johnson, 'Aspects of the historical geography of the 1918-19 influenza pandemic in Britain', PhD thesis, University of Cambridge, 2001, p. 158; Niall P A S Johnson and Juergen Mueller, 'Updating the accounts: global mortality of the 1918-1920

"Spanish Influenza" pandemic', Bull. Hist. Med., 2002, 76: 105-15.

${ }^{4}$ In many countries the peak had already past by the time of the Armistice and general demobilization, but Crosby describes recrudescences of the epidemic associated with Armistice celebrations in the United States. Alfred W Crosby, America's forgotten pandemic: the influenza of 1918, Cambridge University Press, 1989, pp. 85, 105. See also Johnson, op. cit., note 3 above, p. 183 .

${ }^{5}$ The public perception of a full scale epidemic may have been tempered by the muted press reports in combatant nations where the full extent of the death toll
\end{abstract}




\section{Alice Reid}

undoubtedly placed additional strains on society and the economy, these appear to a large extent to have been subsumed into the experience of the war itself. ${ }^{6}$

Research on the influenza pandemic, after a largely dormant period, has enjoyed a recent boom. This has resulted in improved estimates of mortality and morbidity, and descriptions of the course of the epidemic and patterns of response in different places. ${ }^{7}$ These newer studies have focused on the disproportionate adult mortality which was so alarming for those who lived through it, further depleting those generations most affected by the war and heightening social and economic dislocation. The completely abnormal vulnerability of those in the prime of their lives made a stark contrast to the usual age pattern of influenza mortality, which was higher among the youngest and oldest age groups. The experience of Anthony Burgess, described above, reflects this unusual age pattern. Anthony's mother, a young healthy woman, and his older sister of four years died, while he, not much more than a year, was spared. In fact, although those in their twenties and thirties did experience the largest proportionate increases from the very low normal mortality of those age groups, absolute numbers of deaths to infants and children under the age of five were still substantial, and relative increases in this age group were smaller only because initial levels were higher. ${ }^{8}$ Christopher Langford has suggested that the unusual age pattern of the 1918-19 pandemic was due to immunity conferred by previous epidemics among the elderly, and that mortality among the younger age groups was not abnormally low. ${ }^{9}$ Infants and young children are a particularly vulnerable group in any circumstances, and only the year before the pandemic nearly 10 per cent of infants born in England and Wales died before their first birthday. Children whose mothers have died are at particularly high risk, ${ }^{10}$ and it may therefore be more pertinent to ask, not why Anthony's mother died, but why Anthony himself did not.

While young adults undoubtedly did suffer proportionately more than other age groups, this does not mean that others, particularly the very young, were spared. It has been concluded that the "impact of the First World War on British society was inextricable from the influenza epidemic", ${ }^{11}$ but because the very young were not embroiled in the war to the same extent as adults (although the possible effects of war on infant and child health

was not reported. In neutral Spain, the pandemic received far greater prominence in the press, and it was reports in the London press of epidemic influenza in Spain which led to it being called "the Spanish 'flu". Patterson and Pyle, op. cit., note 3 above, p. 7; Johnson, op. cit., note 3 above, pp. 105-9.

${ }^{6}$ Sandra M Tomkins, 'Britain and the influenza pandemic of 1918-19', PhD thesis, University of Cambridge, 1989, ch. 3.

${ }^{7}$ See Johnson, op. cit., note 3 above; Christopher Langford, 'The age pattern of mortality in the 1918-19 influenza pandemic: an attempted explanation based on data for England and Wales', Med. Hist., 2002, 46: 1-20; Johnson and Mueller, op. cit., note 3 above; J S Oxford, A Sefton, R Jackson, N P A S Johnson and R S Daniels, 'Who's that lady?', Nature Medicine, 1999, 5(12): 1351-52; Svenn-Erik Mamelund, 'Spanish influenza mortality of ethnic minorities in Norway 1918-1919', Eur. J. Popul., 2003, 19: $83-102$.

${ }^{8}$ Langford, op. cit., note 7 above, p. 11. See also G Cerasoli, 'Italian pediatricians and the influenza pandemic of 1918-19', Ital. J. Pediatr., 2002, 28: 163-6, p. 164.

${ }^{9}$ Langford, op. cit., note 7 above, pp. 11, 15-16.

${ }^{10}$ Irvine Loudon, Death in childbirth: an international study of maternal care and maternal mortality 1800-1950, Oxford, Clarendon Press, 1992, p. 484, quotes studies showing mortality among infants whose mothers died within one year after the confinement to be four to five and a half times higher than among infants whose mothers did not die.

${ }^{11}$ Sandra M Tomkins, 'The failure of expertise: public health policy in Britain during the 1918-19 influenza epidemic', Soc. Hist. Med., 1992, 5(3): 435-54, p. 453. 


\section{8-1919 Influenza Pandemic and Child Health}

must not be forgotten ${ }^{12}$ ), examination of infants and children may offer the potential for separating the effects of the pandemic from those of the war. This is not meant to imply that the effect of the influenza pandemic on infants and young children can be extrapolated to adults; indeed, this paper demonstrates that there can be a variety of different mechanisms by which influenza can affect health in infancy and childhood. Nor is it intended to suggest that the pandemic cannot be looked at by examining its effect on women, as has been ably done already. This study merely seeks to present another perspective on the pandemic, and therefore aims to isolate the effects of the 1918-19 influenza epidemic from other influences on infant and child health in Derbyshire. The analysis uses an individual level data set of 30,488 infants born between January 1917 and December 1922 to look at mortality rates by cause, while controlling for other influences. It identifies those infants most at risk during the epidemic and judges the direct, indirect and associated effects of the influenza epidemic on infant and child health and survival.

\section{The Influenza Pandemic in England and Wales}

Although contemporary reports attributed the origin of the influenza pandemic to Spain in 1918, hence the name "the Spanish 'flu", it now seems more likely that the virus responsible originated as early as 1915 , and that isolated outbreaks of the disease labelled purulent bronchitis were occurring in England and France in 1916 and 1917. ${ }^{13}$ However, the pandemic did not start in earnest until 1918, with the first of three waves. This "spring" wave hit the United States in March 1918 and Europe in May and June. By July and August it was waning, but was rapidly superseded by the "autumn" wave, a much more lethal strain starting in France in August and spreading throughout Europe and further afield during September and October. A final wave followed in the early months of 1919. The first wave in Britain was relatively mild, although the North and the North Midlands witnessed a sudden change in late June when the number of deaths to young adults increased. Worldwide the second wave was the most virulent, and this was also true for the southern parts of Britain. In the North and the North Midlands the second wave was less dramatic, but sustained, and these regions suffered more than other areas in the third wave.

The estimation of mortality and morbidity rates due to the pandemic is fraught with difficulty, partly connected with the war. With many men serving in the army, mostly overseas, population denominators (the numbers of people at risk) are difficult to determine. Therefore, while there were numerically more deaths among the female civilian population, the Registrar-General estimated the death rate among the civilian male population to have been higher. ${ }^{14}$ Assessment is also complicated by the fact that although many deaths were recorded as a direct result of influenza, the disease would also have contributed, directly or

\footnotetext{
${ }^{12}$ In Britain, available evidence suggests that regular wages and food supplements may have improved infant health during the war (J M Winter, 'The impact of the first world war on civilian health in Britain', Econ. Hist. Rev., 1977, 30: 487-507; idem, 'Aspects of the impact of the first world war on infant mortality in Britain', J. Eur. Econ. Hist., 1982, 11: 713-38).
}

\footnotetext{
${ }^{13}$ These outbreaks shared the same precise clinical and physiological descriptions as the influenza of the pandemic. Oxford, et al., op. cit., note 7 above. See also Johnson, op. cit., note 3 above, pp. 113-21.

${ }^{14}$ Registrar-General, Supplement to the eighty-first annual report of the Registrar-General, Report on the mortality from influenza in England and Wales during the epidemic of 1918-19, London, HMSO, 1920 , p. 5.
} 


\section{Alice Reid}

indirectly, to deaths attributed to other conditions. For example, deaths from pneumonic complications - a direct result of influenza-were often recorded simply as pneumonia. Influenza would also have been a key factor in deaths from other causes among people who might not have died were it not for the presence of the influenza virus. Diagnoses were often confused and record keeping was inadequate ${ }^{15}$ : influenza was not made a notifiable disease until the final stages of the epidemic. Given the similarity of recorded cases of purulent bronchitis, it is also possible that influenza was under-recorded in the early stages of the pandemic and perhaps overstated later. ${ }^{16}$

The recording problems associated with the war mean that many of the official estimates of mortality concentrate on women, and the other problems with recording suggest that it may be most instructive to examine overall, rather than cause-specific, death rates (which sometimes include associated causes and sometimes do not). Until the last quarter, 1918 was a very healthy year for England and Wales, but that was changed completely by the second wave of the epidemic, making 1918 the first year in which deaths (to civilians) outstripped births since records began. It has been estimated that between 30 and 75 per cent of the population was affected by influenza, that around 20 per cent of cases suffered complications, of which 40 per cent died. ${ }^{17}$ The Registrar-General officially attributed 200,000 deaths to the disease. ${ }^{18}$ Figure 1 shows that during the fourth quarter of 1918 when the epidemic was at its most deadly, mortality to women aged 25 to 30 was nearly 600 times higher than it had been for the average of the same quarters of the previous four years.

\section{"Woe unto Them that are with Child": ${ }^{19}$ Influenza and Pregnancy}

Figure 1 demonstrates clearly the peculiar phenomenon during the "Spanish 'flu" of highest proportionate increases in mortality among young adults, particularly those in their twenties and thirties. For women, these are the child-bearing years, and pregnant women were at particularly high risk of becoming infected. The mortality of all women aged between 15 and 49 due to influenza during the epidemic was 4.9 per thousand, but that of pregnant women was between 5.3 and 5.7 per thousand. ${ }^{20}$ This statistic is elucidated by studies performed in the USA, where it was found that, compared to women not recorded as pregnant, expectant women had a 50 per cent higher chance of developing pneumonic complications. Once complications had developed, such women were 50 per cent more likely to die. ${ }^{21}$ Studies of the two subsequent epidemics and of non-epidemic seasons have shown that pregnant women are at particularly high risk from influenza towards the end of their pregnancy. In the "Asian 'flu" pandemic of 1957 half of all influenza-related deaths

\footnotetext{
${ }^{15}$ Fred R van Hartesveldt, 'Manchester', in van Hartesveldt (ed.), op. cit., note 2 above, pp. 91-103, on p. 91.

${ }^{16}$ Oxford, et al., op. cit., note 7 above, p. 1351.

${ }^{17}$ Tomkins, op. cit., note 6 above, pp. 26, 30 .

${ }^{18}$ Registrar-General, op. cit., note 14 above, p. 7.

${ }^{19}$ Lancet, 18 Oct. 1919, ii, p. 699, quoted in Johnson, op. cit., note 3 above, p. 265.

${ }^{20}$ A W Bourne, 'Influenza: pregnancy, labour, the puerperium, and diseases of women', in F G

Crookshank (ed.), Influenza: essays by several authors,
}

London, Heinemann, 1922, pp. 433-43, on pp. 439-40. This difference is probably understated as pregnancy was not always noted on the death certificate and it is probable that many of the other women in the child-bearing ages who died were also pregnant.

${ }^{21}$ John W Harris, 'Influenza occurring in pregnant women, a statistical study of thirteen hundred and fifty cases', J. Am. med. Assoc., 1919, 72 (3 April): 978-80, p. 798. See also Paul A Buelow, 'Chicago', in van Hartesveldt, op. cit., note 2 above, $119-45$, on p. 131 , who states that 46 per cent of all 


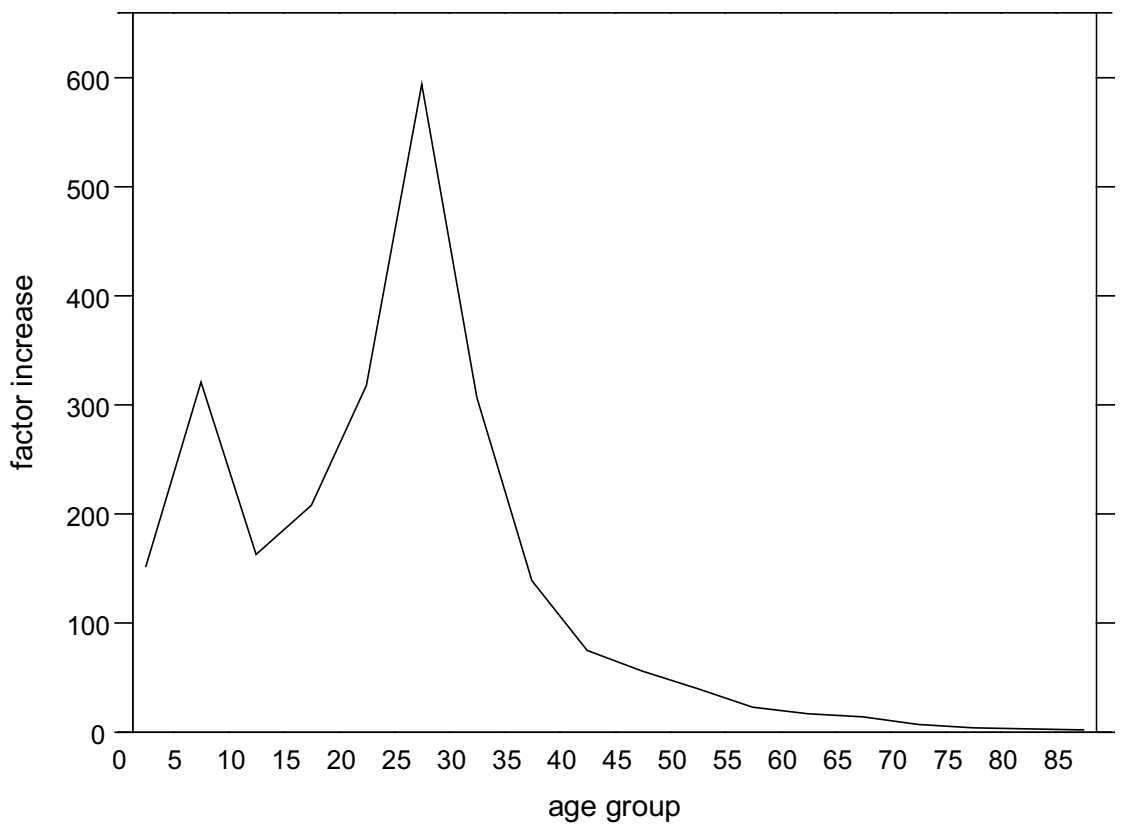

Figure 1: Factor increase in female mortality during the 'flu epidemic, fourth quarter of 1918 compared to average of fourth quarters 1914-17. (Source: Registrar-General, Supplement to the eighty-first annual report of the Registrar-General, Report on the mortality from influenza in England and Wales during the epidemic of 1918-19, London, HMSO, 1920, p. 8.)

among women of childbearing age occurred in those who were pregnant. ${ }^{22}$ Furthermore, a recent study of non-epidemic risk demonstrated that being in a late stage of pregnancy was an independent risk factor for hospitalization for influenza, pneumonia, and a broader range of acute cardiopulmonary conditions, although actual mortality was rare. Women in their second trimester of pregnancy had an influenza-attributable risk five times that of postpartum women, a factor which rose to nine for those in their third trimester. ${ }^{23}$ This susceptibility of pregnant women may be due to changes in blood circulation, ${ }^{24}$ reduced functional capacity of the lungs, ${ }^{25}$ or to the immunosuppression necessary to prevent rejection of the foetus (sometimes referred to as "pregnancy associated immunodeficiency syndrome" (PAIDS)) which also leaves women more vulnerable to infection. ${ }^{26}$

hospitalized pregnant women died from 'flu and pneumonia in Chicago.

${ }^{22}$ See Sir Charles H Stuart-Harris, Geoffrey C Schild and John S Oxford, Influenza: the viruses and the disease, 2nd ed., London, Edward Arnold, 1985, p. 105; Edwin D Kilbourne, Influenza, New York, Plenum Medical, 1987, p. 163.

${ }^{23}$ Kathleen Maletic Neuzil, George W Reed, Edward F Mitchel, Lone Simonsen and Marie R Griffin, 'Impact of influenza on acute cardiopulmonary hospitalizations in pregnant women', Am. J. Epidemiol., 1998, 148: 1094-102.

${ }^{24}$ Kilbourne, op. cit., note 22 above, p. 163.

${ }^{25}$ Neuzil, et al., op. cit., note 23 above, p. 1101.

${ }^{26} \mathrm{E}$ Weinberg, 'Pregnancy and resistance to infectious disease', Rev. Infect. Dis., 1984, 6: 814-31. Not to be confused with PAIDS referring to paediatric acquired immunodeficiency syndrome (see Arthur A Ammann, Diane W Wara and Mort J Cowan, 'Pediatric acquired immunodeficiency syndrome', Ann. N. Y. Acad. Sci., 1984, 437: 340-9). 


\section{Alice Reid}

The well-established increased risk to pregnant women is likely to have been heightened during 1918-19 due to the unusual age structure of influenza in this particular epidemic, and there is evidence that influenza infection may also have precipitated foetal loss. In England and Wales the death rate from spontaneous abortion in 1917 was 0.16 per thousand (one in 6,302 pregnancies), whereas during the epidemic the death rate from only those miscarriages linked to influenza was ten times greater at 1.60 per thousand (one in 624 pregnancies). ${ }^{27}$ If influenza could provoke this level of increase in such deaths, it is likely that it was responsible for a great many more non-fatal spontaneous abortions. In the USA, pregnancy was interrupted in 26 per cent of uncomplicated cases of influenza and in 52 per cent of cases complicated by pneumonia. ${ }^{28}$ Foetal loss and premature delivery may also have generated a higher number of stillbirths and premature live infants during or shortly after the pandemic. This is corroborated by evidence that higher rates of early neonatal mortality after four of the five influenza epidemics between 1948 and 1971 were due to an increase in the prematurity rate, probably as a result of infection to mothers in the first or second trimesters. ${ }^{29}$ However there has been little other evidence to support the effect of influenza on the premature termination of pregnancy or stillbirth. ${ }^{30}$

A similar uncertainty hangs over the effect of maternal influenza during pregnancy on the risk of birth defects. Although there is some evidence for exposure during the first trimester increasing the occurrence of central nervous system defects (particularly anencephaly), circulatory malfunctions, cleft palate and reduction deformities, ${ }^{31}$ there is also evidence against such associations. J S McKenzie and M Houghton, in their review of the literature, conclude that no direct association between influenza infection during pregnancy and congenital malformations can be substantiated, except for cleft lip and reduction deformities for which the effect is small. ${ }^{32}$ They do not rule out an indirect association, however.

The "Spanish 'flu" therefore hit pregnant women hard, with the consequent effects of increased stillbirths and possibly also more prematurity, which would produce more infants subject to the high risks of all pre-term or small infants. Maternal influenza may also have affected the health of infants and children by its repercussions on the quality of care a mother was able to give her child. Infants whose mothers die are generally at greater risk of death, partly through the cessation of breast-feeding. A severe, but non-fatal, illness in the mother could curtail her ability to breast-feed, thus also increasing the risks for the infant. Figure 1 shows that although the proportionate increase in mortality was not as high as in adulthood, deaths among infants and young children did increase by a factor of between 150 and 300 during the "Spanish 'flu" of 1918-19. Many such young people may have died directly from influenza itself, but this paper attempts to evaluate the different ways in which a mother's illness or death might have affected her child's chances of survival, and compares them with the direct effects of the influenza virus on infants and children.

\footnotetext{
${ }^{27}$ Bourne, op. cit., note 20 above, p. 437.

${ }^{28}$ Harris, op. cit., note 21 above, p. 979 . See also Johnson, op. cit., note 3 above, p. 265, for similar statistics for Paris and Sydney.

${ }^{29} \mathrm{G}$ Wynne Griffith, A M Adelstein, P M Lambert, J A C Weatherall, 'Influenza and infant mortality', Br. med. J., 1972, iii: 553-6.

${ }^{30}$ See J S MacKenzie and M Houghton, 'Influenza infections during pregnancy: association with
}

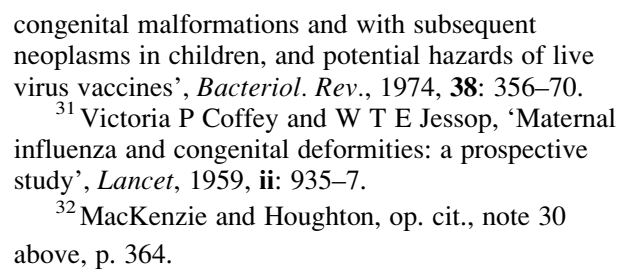
neoplasms in children, and potential hazards of live virus vaccines', Bacteriol. Rev., 1974, 38: 356-70.

${ }^{31}$ Victoria P Coffey and W T E Jessop, 'Maternal influenza and congenital deformities: a prospective study', Lancet, 1959, ii: 935-7.

${ }^{32}$ MacKenzie and Houghton, op. cit., note 30 above, p. 364 . 


\section{8-1919 Influenza Pandemic and Child Health}

\section{The Data Source}

Data sources which might enable these issues to be addressed are rare for England and Wales, but this paper uses a set of notification of births registers drawn up to enable health visitors to visit infants soon after birth and periodically thereafter until a maximum age of five years. The ledgers include both live and still births and also record information about the socio-economic situation of the household (parents' occupations, the number of rooms in the house) and demographic information such as multiple birth, parity, and so on. Notes made by the health visitors during their visits relating to the method of feeding the child, its health and development were also transcribed. The records include all 30,488 births occurring in the rural and small town areas of western and southern Derbyshire between January 1917 and December 1922. The data set yields high quality individual level longitudinal data which is ideal for the purpose of this paper. ${ }^{33}$

\section{Influenza in Derbyshire}

Although this paper will concentrate on the effects of influenza on the very young, it is instructive to put this into context by describing the influenza epidemic in Derbyshire generally. Figure 2 shows the amalgamated numbers of deaths from influenza in the county and municipal boroughs for which numbers were recorded separately, ${ }^{34}$ and of those in the remaining towns and rural areas of Derbyshire. ${ }^{35}$ In common with many urban areas, Derbyshire towns witnessed slightly earlier mortality peaks in each wave of the epidemic than the rural areas, a characteristic which Niall Johnson has suggested is linked to the spread of the virus along routes of communication and diffusion out into more sparsely populated districts. He also suggested that northern regions suffered more than southern. ${ }^{36}$ Having a greater total population, numbers of deaths were higher in the "rest of Derbyshire" than in the towns, but the chance of death was not appreciably different, as indicated by the death rates shown in bold in Figure 3. This Figure also shows weekly death rates for London, for cities and large towns in the North Midlands (apart from Derbyshire, which would normally be classed as part of that region), the West Midlands, and all England and Wales, and for all other areas in the North Midlands (not including Derbyshire), the West Midlands and all England and Wales, which allow Derbyshire's experience of the influenza pandemic to be compared to other places in England and Wales. ${ }^{37}$ The diagram shows that influenza

\footnotetext{
${ }^{33}$ The birth registers are temporarily housed in the Cambridge Group for the History of Population and Social Structure, on loan from the MRC Unit in Southampton. The data set is described in more detail elsewhere. See Alice Reid, 'Infant and child health and mortality in Derbyshire from the Great War to the mid1920s', PhD thesis, University of Cambridge, 1999; idem, 'Neonatal mortality and stillbirths in early twentieth century Derbyshire, England', Popul. Stud., 2001, 55(3): 213-32; idem, 'Infant feeding and post neonatal mortality in Derbyshire, England, in the early twentieth century', Popul. Stud., 2002, 56(2):151-66.

${ }^{34}$ These were Derby CB, Chesterfield MB, Glossop $\mathrm{MB}$, and Ilkeston MB. None of these towns, nor Buxton $\mathrm{MB}$, contributed to the data set.
}

\footnotetext{
${ }^{35}$ The data on which this graph was based were kindly provided by Niall Johnson.

${ }^{36}$ See Johnson, op. cit., note 3, pp. 320-6.

${ }^{37}$ The rest of the North Midlands includes Lincolnshire, Nottinghamshire, Rutland, and Leicestershire (and it would normally include Derbyshire, which is here shown separately). The West Midlands consists of Gloucestershire, Herefordshire, Worcestershire, Warwickshire, Shropshire, and Staffordshire. Cities and large towns include county boroughs, London boroughs, and metropolitan boroughs and large urban areas with populations greater than 20,000. These data are derived from the data set SN4350 '1918-1919 influenza pandemic mortality in England and Wales' in the UK data archive,
} 


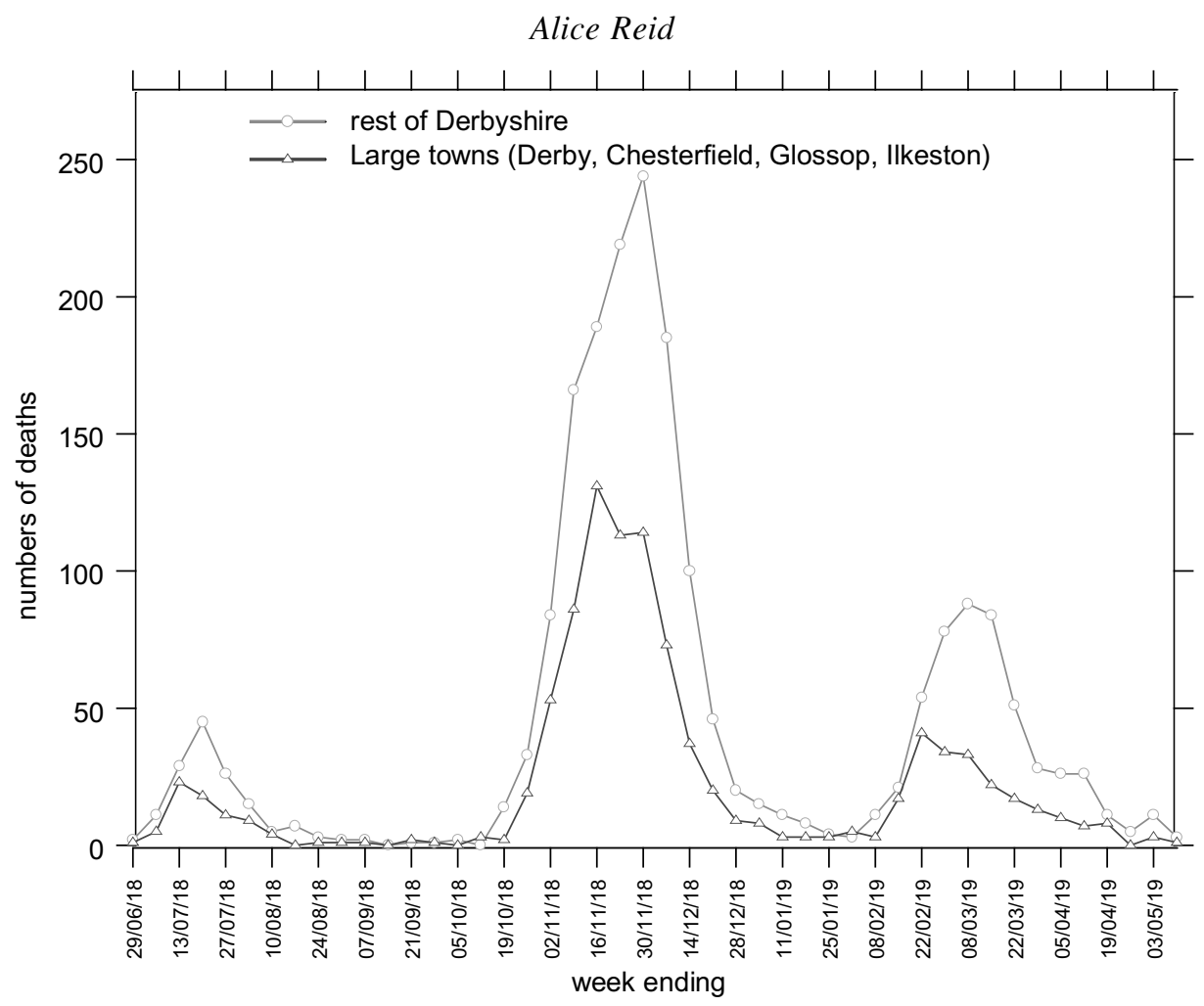

Figure 2: Weekly numbers of deaths from influenza in Derbyshire from the week ending 29 June 1918 until the week ending 3 May 1919. (Source: Registrar-General, Supplement to the eighty-first annual report of the Registrar-General, Report on the mortality from influenza in England and Wales during the epidemic of 1918-19, London, HMSO, 1920. Figures provided by Niall Johnson.)

mortality in the second wave hit London earlier than combined figures for the Midlands and other parts of the country. The epidemic travelled northwards, through the West Midlands, Derbyshire, and the rest of the North Midlands, climaxing in the urban areas of each district before the less densely populated places, and getting progressively more lethal as it travelled.

Weekly data as shown in Figures 2 and 3 are of great value in distinguishing different patterns in an epidemic with relatively short-lived periods of intense activity, and use of such data is possible where there are large numbers of events. With smaller groups, such as will be examined below, the fluctuations in weekly deaths or death rates produced by small numbers mean that it is easier to compare monthly data. As a comparison with what follows, the monthly influenza mortality rates for the large urban areas and the "rest of Derbyshire"

created by Niall Johnson. The original published source was the Registrar-General, op. cit., note 14 above, pp. $48-80$. 
1918-1919 Influenza Pandemic and Child Health

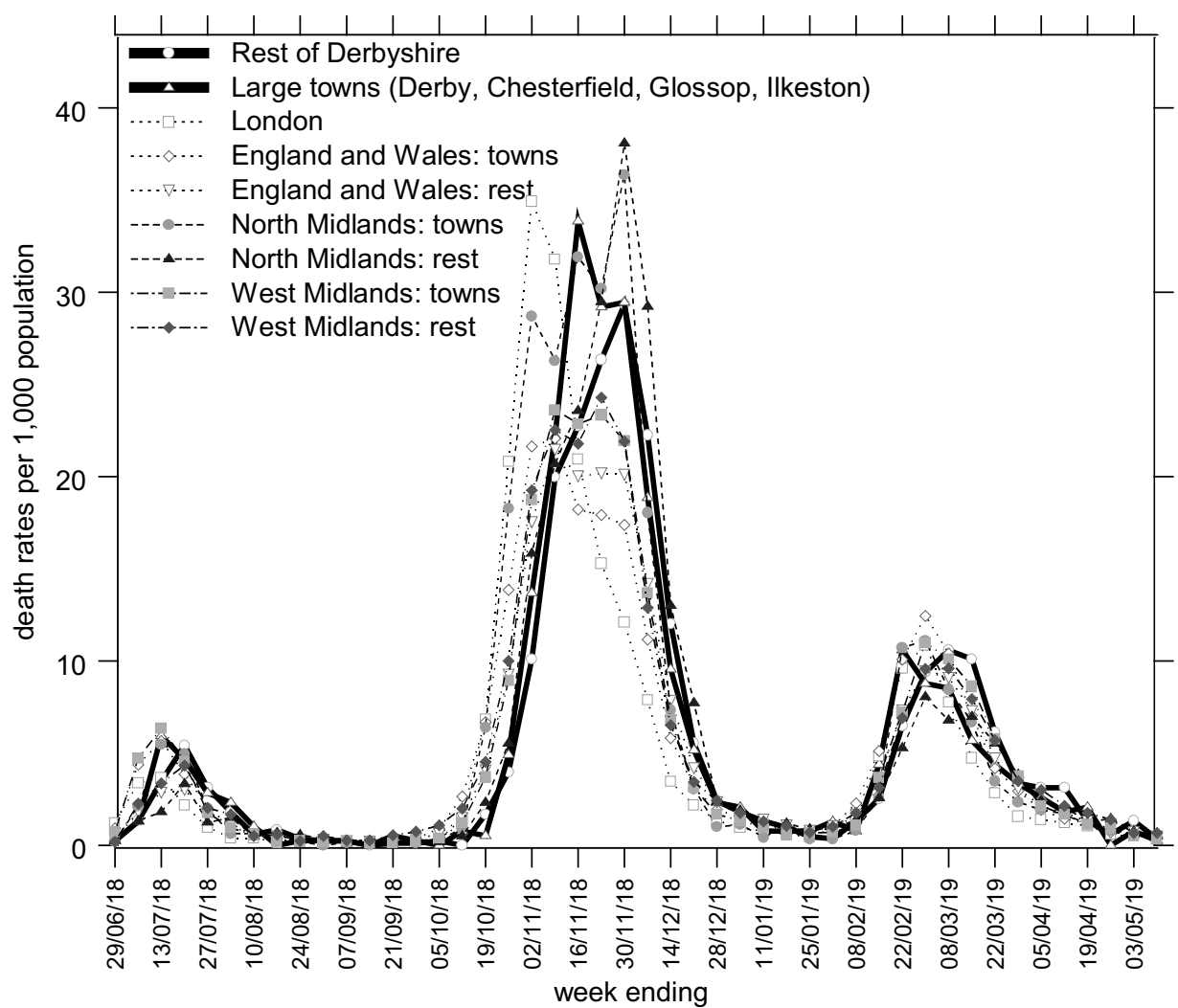

Figure 3: Weekly death rates from influenza in Derbyshire and other areas from the week ending 29 June 1918 until the week ending 3 May 1919. (Source: These data are derived from the data set SN4350 '1918-1919 influenza pandemic mortality in England and Wales' in the UK data archive, created by Niall Johnson. The original published source was the Registrar General, Supplement to the eighty-first annual report of the Registrar-General, Report on the mortality from influenza in England and Wales during the epidemic of 1918-19, London, HMSO, 1920, pp. 48-80.)

are shown in Figure 4, and demonstrate that the more subtle differences in timing visible with weekly figures are lost by monthly data.

The health visitor data set used to examine the effect on infants and children relates to a sub-set of the "rest of Derbyshire", ${ }^{38}$ and annual influenza deaths by administrative unit given in the Registrar-General's annual reports show that the area covered by the data set contributed 52 per cent of all influenza deaths occurring in the wider area in 1918 and 1919. The same source demonstrates that 3.67 per cent of influenza deaths in Derbyshire were of

\footnotetext{
${ }^{38}$ The data set excludes the County Borough of Derby, the Municipal Boroughs of Ilkeston,

Glossop, Buxton, and Chesterfield, and the rural and
}

small town area around Chesterfield, as these were administered separately. 


\section{Alice Reid}

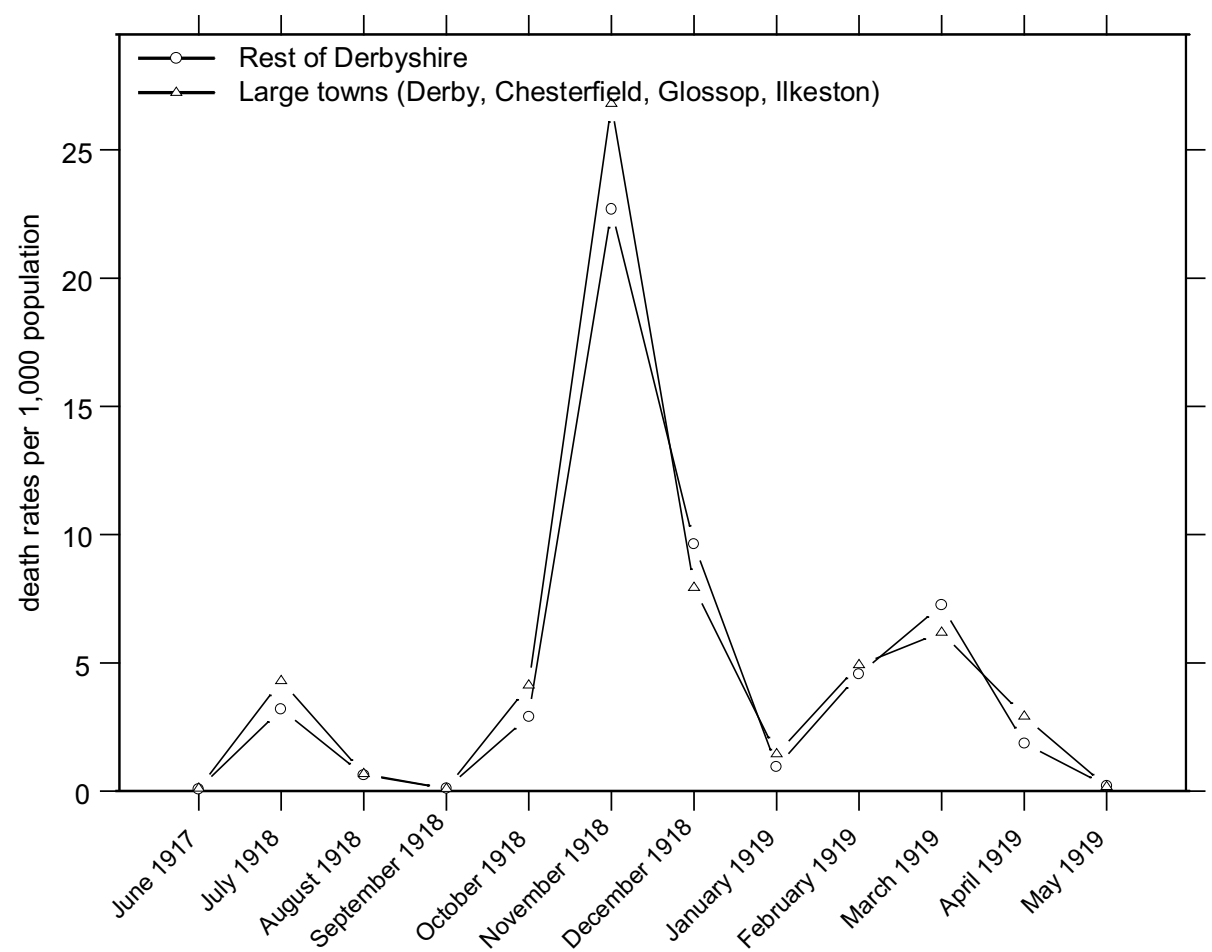

Figure 4: Monthly death rates from influenza in Derbyshire during the 1918-19 epidemic. (Source: Registrar-General, Supplement to the eighty-first annual report of the Registrar-General, Report on the mortality from influenza in England and Wales during the epidemic of 1918-19, London, HMSO, 1920. Derived from figures provided by Niall Johnson.)

infants under the age of one, and on the basis of this, and a small adjustment for the fact that the areas covered by the data set had lower mortality than the rest of Derbyshire, we could expect 32 infant deaths attributed to influenza in the data set, as set out in Table 1. In fact the data set records 23 deaths, fewer than expected because some infants had already ceased to be visited by the time they were one year old, and deaths of infants no longer visited were not recorded in the data set. Similarly, as also shown in Table 1, the published figures could lead us to expect 37 influenza deaths between the ages of one and two. In fact we see only six as, again, some deaths would have been of children who were no longer being seen by health visitors and some deaths of one-year-olds in 1918 would have been of children born in late 1916 and not yet turned two. We cannot examine influenza deaths at older ages of childhood as none of the children covered by the data set were more than two years old during the worst part of the epidemic. However, we may observe some maternal mortality: on the basis of the published county figures, there were probably around 158 deaths of women aged between 25 and 45, the prime childbearing period, in the area covered by the data set. Only a small percentage of these were likely to have been mothers of children under the age of two, however. As shown in Table 1, on the basis of national fertility rates, between 15 and 20 per cent of women aged 25 to 45 had children under the age of two, therefore we might expect 


\section{8-1919 Influenza Pandemic and Child Health}

Table 1

Influenza deaths in Derbyshire 1918-19: calculation of deaths expected in the health visitor data set

\begin{tabular}{|c|c|c|c|c|c|}
\hline & & & Infants & Age 1 to 2 & $\begin{array}{l}\text { Women } \\
\text { age } 25-45\end{array}$ \\
\hline A & Influenza deaths in Derbyshire (incl. Derby) & 2993 & 110 & 127 & 545 \\
\hline B & $\begin{array}{l}\text { Influenza deaths to age group as a proportion } \\
\text { of all influenza deaths in the county } \\
\text { (calculated from A) }\end{array}$ & & 0.036 & 0.042 & 0.182 \\
\hline $\mathrm{C}$ & $\begin{array}{l}\text { Number of influenza deaths in the } \\
\text { area covered by the health visitor data set }\end{array}$ & 1036 & & & \\
\hline $\mathrm{D}$ & $\begin{array}{l}\text { Estimated numbers of influenza } \\
\text { deaths in the area covered by the } \\
\text { data set on the basis of the proportions in B }\end{array}$ & & 38 & 44 & 189 \\
\hline $\mathrm{E}$ & $\begin{array}{l}\text { Adjustment for lower mortality in } \\
\text { the area covered by the data set }\left({ }^{*} 0.839\right)\end{array}$ & & 32 & 37 & 158 \\
\hline $\mathrm{F}$ & $\begin{array}{l}\text { Estimated births per year to women aged } \\
25-49\end{array}$ & 8494 & & & \\
\hline G & $\begin{array}{l}\text { Estimated proportion of women aged } 25-45 \\
\text { with a child less than two years old, assuming } \\
\text { each woman had only one child in the } \\
\text { time period. }\end{array}$ & 0.201 & & & \\
\hline $\mathrm{H}$ & $\begin{array}{l}\text { Estimated proportion of women aged } \\
25-45 \text { with a child less than two } \\
\text { years old, assuming half of those women } \\
\text { had two children in the two years. }\end{array}$ & 0.150 & & & \\
\hline I & $\begin{array}{l}\text { Estimated deaths of women in the data set } \\
\text { (i.e. mothers of children under the age } \\
\text { of two), based on G }\end{array}$ & & & & 32 \\
\hline $\mathrm{J}$ & $\begin{array}{l}\text { Estimated deaths of women in the data } \\
\text { set (i.e. mothers of children under the } \\
\text { age of two), based on } \mathrm{H}\end{array}$ & & & & 24 \\
\hline
\end{tabular}

Sources:

A, C: Eighty-first annual report of the Registrar-General of births, deaths, and marriages in England and Wales (1918), Cmd. 608 1920, pp. 245, 282 and 346-8. Eighty-second annual report of the Registrar-General of births, deaths, and marriages in England and Wales (1919), Cmd. 1017 1920, pp. 315, 352 and 416-18.

E: based on ratio of the infant mortality rate in the area covered by the data set (70.59) to that in all Derbyshire (84.13), calculated from Registrar-General's annual reports. See Alice Reid, 'Neonatal mortality and stillbirths in early twentieth century Derbyshire, England', Popul. Stud., 2001, 55 (3): 213-32, p. 215, Table 1.

F: calculated from age-specific marital fertility rates for England and Wales for 1922 (Robert Woods, The demography of Victorian England and Wales, Cambridge University Press, 2000, p. 130), and the numbers of married women in Derbyshire in each 5-year age group in 1921, as given in the Census of England and Wales 1921: County of Derby, 1923, London, HMSO, Table 14, p. 39.

G: based on two years of births to women in the age group, divided by the number of all women in the age group. 


\section{Alice Reid}

between 24 and 32 deaths of mothers in our data set. In fact we see 16 deaths of mothers during the epidemic year directly attributed to the 'flu, and a further 30 with insufficient causal information, but in which 'flu might have been implicated.

It is clear that the data set records fewer deaths from influenza than actually occurred in the area covered, and it can be shown that a similar error appears with mortality from any cause. The shortfall is due to the fact that health visitors stopped visiting some infants, and the deaths of these infants are not recorded. Fortunately this can be taken account of using life table techniques and hazard modelling, ${ }^{39}$ which calculate a series of rates using those known to be in observation at each unit of time, and which produce overall infant mortality rates and early childhood (1-5 years) mortality rates not significantly different to those calculated from vital registration. The infant mortality from the data set is 68.70 infant deaths per thousand births, and that calculated from vital registration is 70.59; the corresponding figures for the early childhood mortality rate are 29.0 and 29.7 deaths per thousand children in the age group. ${ }^{40}$ There is no reason to suppose that influenza deaths were any less accurately recorded than other infant deaths. In fact, given the difficulty of accurately ascribing causes to many infant deaths, ${ }^{41}$ those from influenza might have been more easily recognized, and thus more correctly recorded than others, consequently the data set can be relied upon to produce a reasonably exact reflection of the risks of dying from influenza mortality during the epidemic.

\section{The Effects of the Influenza Epidemic on Infant and Child Mortality}

Figure 5 shows indexed monthly post-neonatal mortality rates for the influenza epidemic in comparison with the other years in the data set. The x-axis shows the year running from July 1918 to June 1919, to capture the entire epidemic year. The graph shows that the second wave, peaking in Derbyshire in November 1918, raised post-neonatal mortality well above its normal seasonal winter peak. Figure 6 shows that mortality for the second year of life was strongly affected in the first and third waves as well as the second, the third wave peaking slightly earlier than for all age groups. In contrast neonatal mortality and the stillbirth rate (Figures 7 and 8) show different patterns. Neonatal mortality appears to have peaked in the third wave: mortality rates were highest in February but also high in April and June. This three-pronged pattern might suggest a lagged effect of the three waves (although the lag is not the same in each case), which would be consistent with the hypothesis that influenza in the first or second trimester of pregnancy increased prematurity rates and consequently neonatal mortality. ${ }^{42}$ The effect on stillbirths appears to have been concentrated in the second wave with its prolonged high rates. As with neonatal mortality, however, the September peak could represent the delayed first wave, but with a shorter lag, and the question then arises of why the second wave appears to have had an immediate effect.

\footnotetext{
${ }^{39}$ For more information on life table techniques and hazard modelling, see David W Hosmer and Stanley Lemenshow, Applied survival analysis: regression modeling of time to event data, New York and Chichester, John Wiley, 1999.

${ }^{40}$ Reid, 'Infant and child health', op. cit., note 33 above, p. 215. For the 1-5 figure, a life table measure
}

was generated by the data set and subsequently transformed into an age-specific death rate.

${ }^{41}$ Naomi Williams, 'The reporting and classification of causes of death in mid-nineteenthcentury England: the example of Sheffield', Hist. Methods, 1996, 29(2): 58-71.

${ }^{42}$ Wynne Griffith, op. cit., note 29 above. 
1918-1919 Influenza Pandemic and Child Health

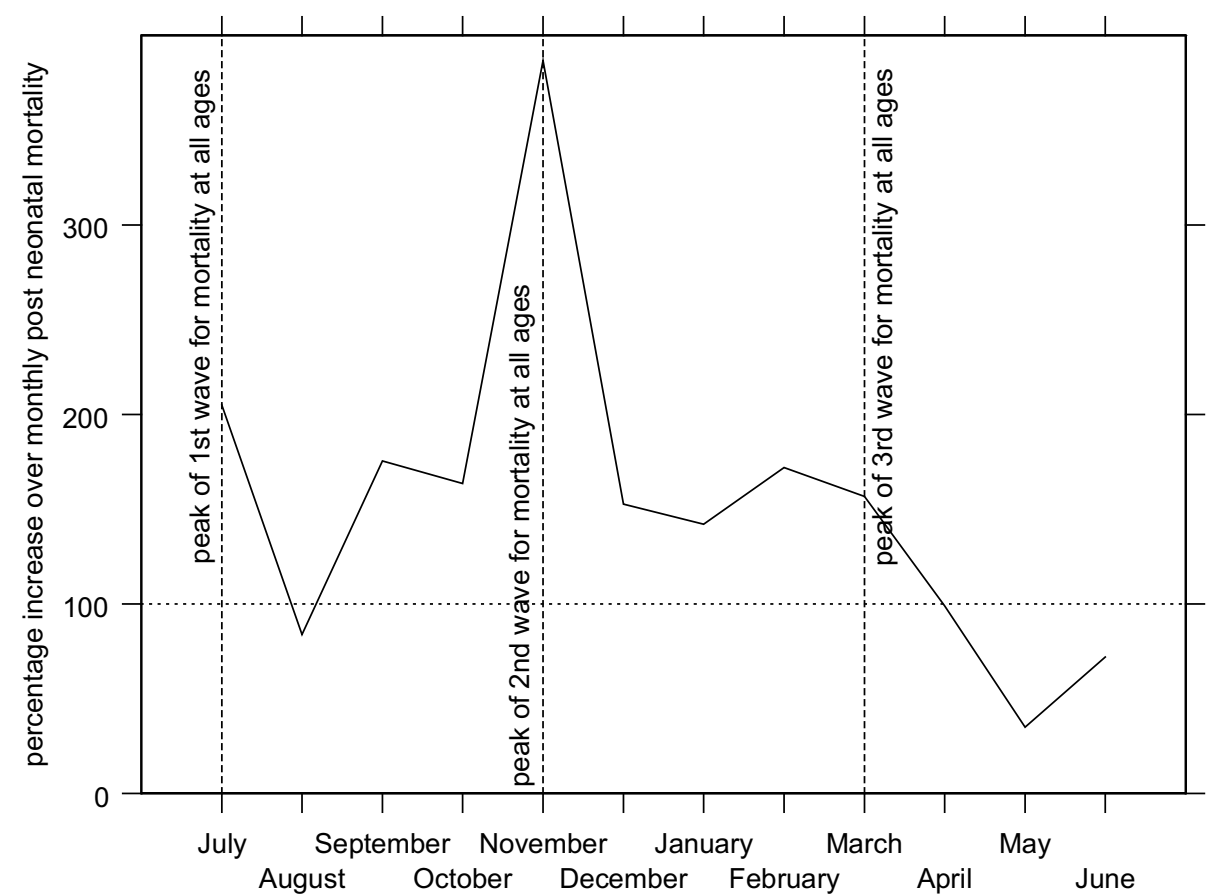

Figure 5: Indexed post-neonatal period monthly death rates in Derbyshire, late 1918 and early 1919 (monthly averages for other years 1917-22 =100). (Source: Derbyshire health visitor data.)

Figures 7 and 8 are drawn to the same scale as Figures 5 and 6, revealing that although in some months the risks of neonatal mortality and stillbirth were around twice as high for the same months in other years, the increases in the risks of death before one month of age were not as great as those for post-neonatal and early child mortality.

Period death rates identify the time periods at which more deaths occurred, but the comparison of different influences on health and survival needs the identification of children at risk of dying during the epidemic. In other words, it is necessary to isolate a cohort of those who were born in a given time and were therefore in a particular age group during the epidemic. Children at highest risk of stillbirth can be identified simply by their dates of birth: those born between September 1918 and January 1919 were at highest risk and period and cohort rates are identical. It is also easy to identify those at risk of neonatal mortality during the epidemic by date of birth, because as the neonatal period is relatively short, most infants spent all of it or none of it during the epidemic. Also, because the period of risk is just one month following the birth, the cohort death rates for neonatal mortality in Figure 9 show a similar pattern to Figure 7 (although different enough to detect a clearer three month lag from the first and second waves of the epidemic to peaks in October and February). Those born between January and April 1919 are identified as those at greatest risk of neonatal mortality during the epidemic.

It is more difficult to identify those at risk of post-neonatal mortality because infants are at risk for a much longer time. For example, children born in early 1918 would have been in 


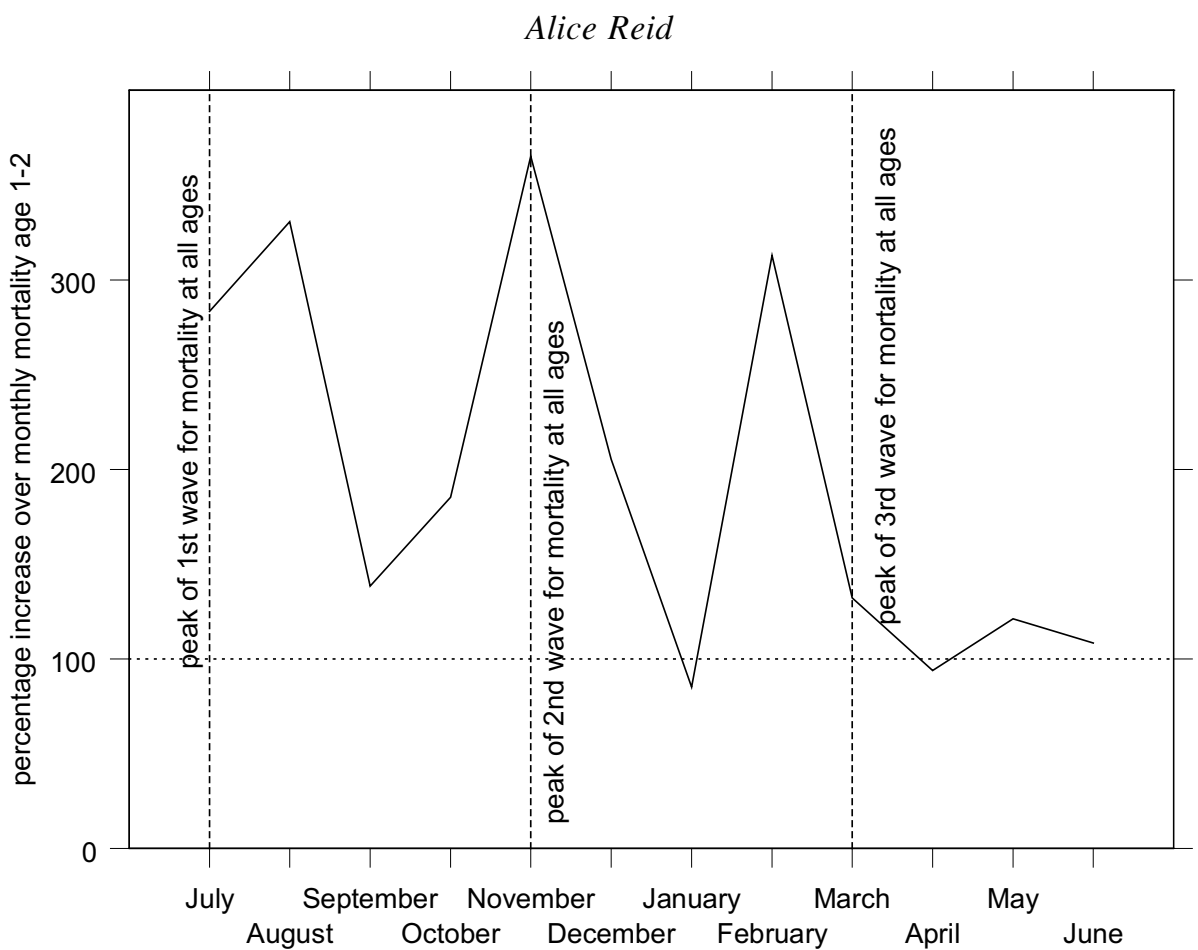

Figure 6: Indexed early childhood period monthly death rates in Derbyshire, late 1918 and early 1919 (monthly averages for other years $1917-22=100$ ). (Source: Derbyshire health visitor data.)

peril from this form of death towards the end of their first year, at the beginning of the epidemic. Children born at the end of 1918 would have been at risk only during their early post-neonatal period, and at the end of the epidemic. Children born in the spring and early summer of 1918 would have been exposed to the entire epidemic during their post-neonatal period. Figure 10 shows monthly post-neonatal mortality rates, distinguishing those born in each month of 1918 from those born in the corresponding month of other years, and demonstrates that, unsurprisingly, all infants born in 1918 were at elevated risk from the epidemic, as they all spent at least part of their post-neonatal lives exposed to the influenza virus. Those born during the summer of 1918 (particularly between July and September) had a much higher risk of dying. Such infants were in their early post-neonatal period at the peak of the second, most virulent wave, and were still in this age group during the third wave. Those born in February 1918, spending the first two waves in this age group had the greatest excess risk, and it is unclear why those infants born in March and April 1918, who were exposed to all three waves, did not suffer as much. The problem of identification is more acute for early child mortality and has not been attempted.

Once the cohorts at most risk have been identified, it is possible to quantify and compare the result of exposure to the epidemic of a child born at a particular date with other influences such as multiple birth, legitimacy, parental occupation, number of rooms in the house, urban/rural residence and so on. Such a comparison can be made by using 
1918-1919 Influenza Pandemic and Child Health

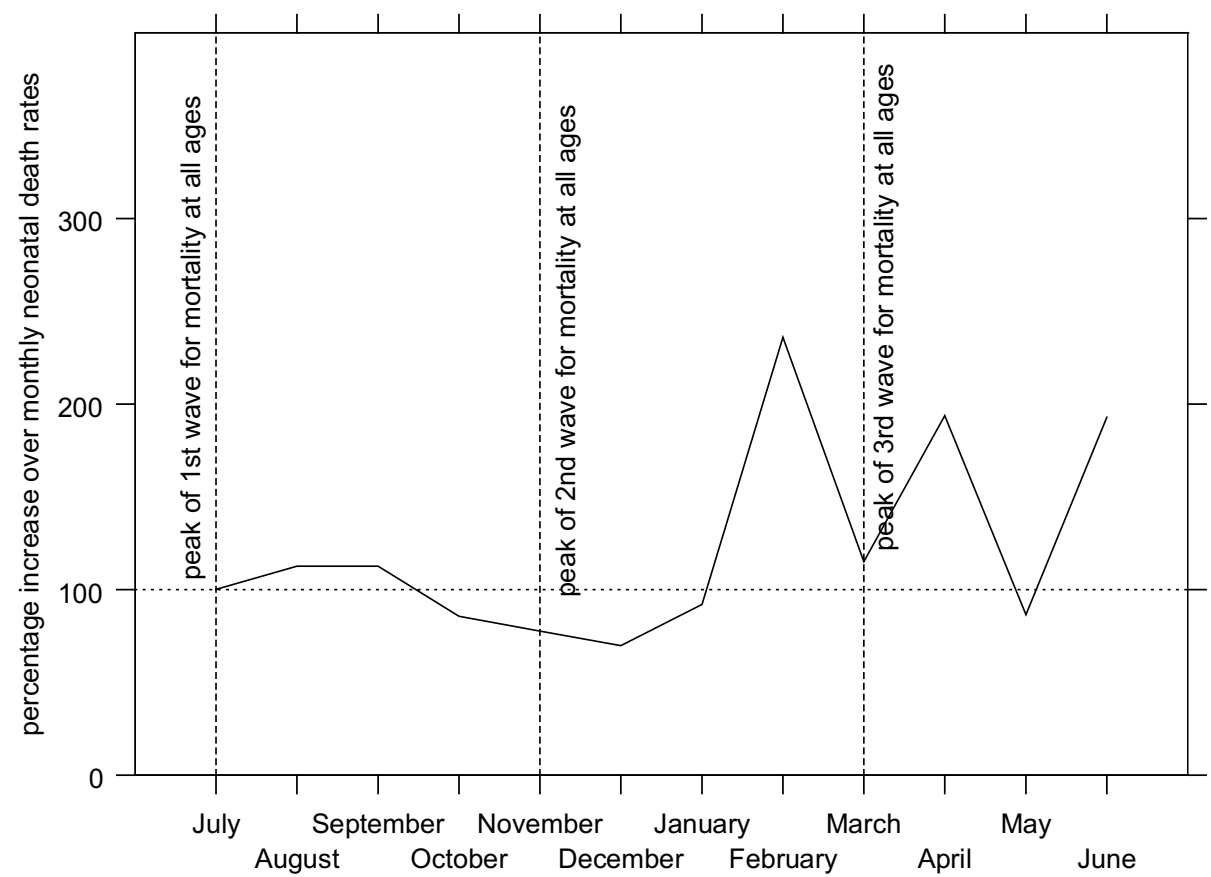

Figure 7: Indexed neonatal period monthly death rates in Derbyshire, late 1918 and early 1919 (monthly averages for other years 1917-22 =100). (Source: Derbyshire health visitor data.)

multivariate hazard analysis (for post-neonatal and neonatal mortality) and logistic analysis (for the risk of stillbirth) and the following analyses show the risks of babies being stillborn, of dying in the neonatal period, and of dying in the post-neonatal period associated with birth during the influenza epidemic, while controlling for the effect of other influences on the risk of mortality. ${ }^{43}$ In the tables each odds ratio is derived from a different analysis, either examining risk of different forms of death (i.e. stillbirth, neonatal mortality, or postneonatal mortality), or assessing the risks associated with being born at a different time period. The odds ratios show the multiplicative increase in the risk of death for infants born during particular time periods and thus at risk during the influenza epidemic. Thus Table 2 shows that infants born at any time in the second or third waves of the epidemic (July

\footnotetext{
${ }^{43}$ Independent variables significantly increasing the risk of stillbirth were multiple birth, male sex, parity one then increasing linearly with parity after parity two, having a doctor present at the birth (as opposed to just a midwife), father being manual social class, mother having been employed during pregnancy, and being born in winter months (October to April). Those significantly increasing the risk of neonatal mortality were multiple birth, male sex, parities four and above, having a doctor present at birth, being born in winter months, living in a more densely populated district, and
}

living in a district where over half the population had a privy midden as opposed to more sanitary toilet facility (see Reid, 'Neonatal mortality', op. cit., note 33 above, pp. 216-21). Independent variables significantly increasing the risk of post-neonatal mortality were multiple birth, male sex, illegitimacy, higher parities, having been artificially fed by the end of the first month, living in a mining district, having fewer than four rooms in the house, and living at higher altitude (see Reid, 'Infant feeding', op. cit., note 33 above, pp. 155-7). 


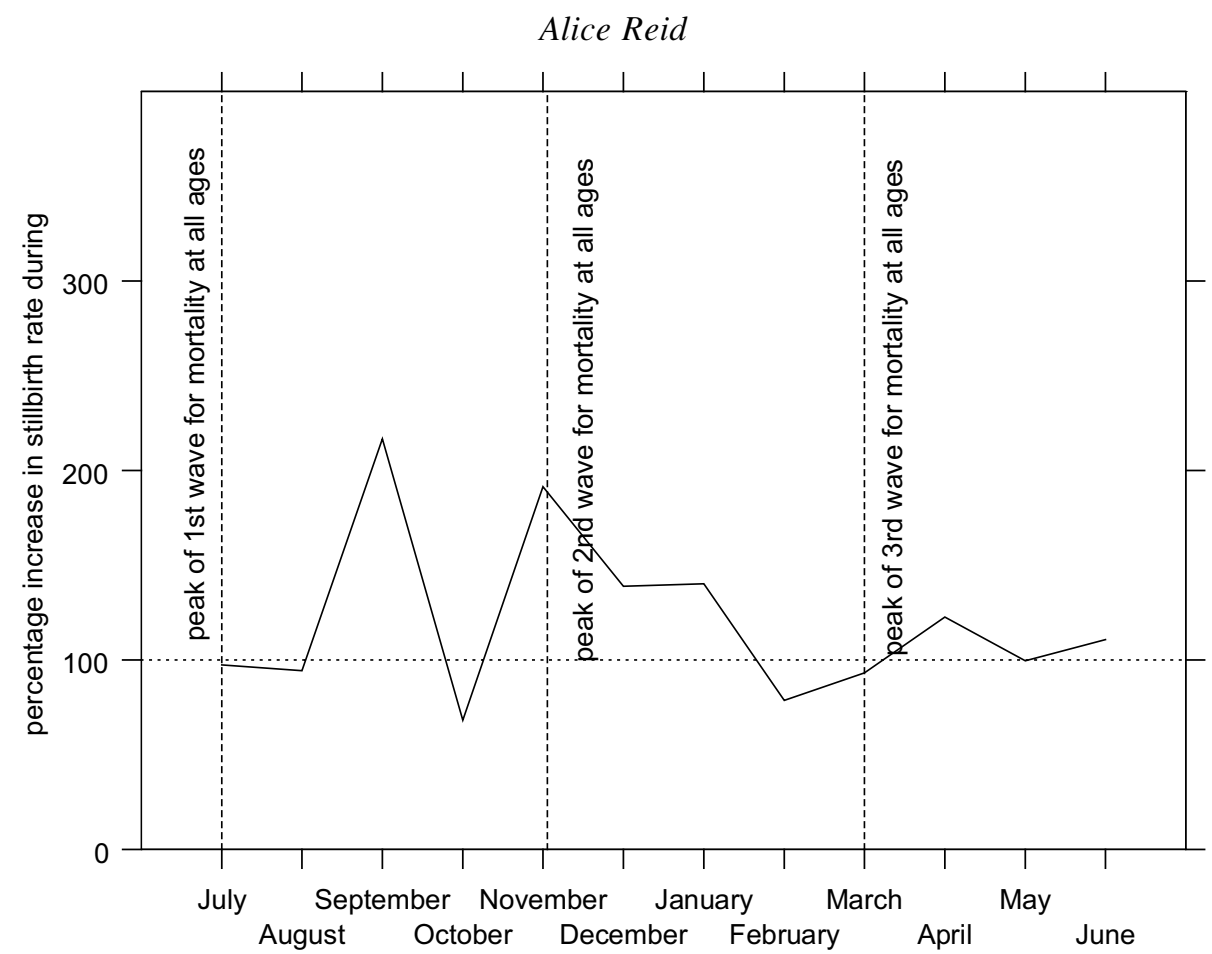

Figure 8: Indexed period stillbirth rates in Derbyshire, late 1918 and early 1919 (monthly averages for other years $1917-22=100$ ). (Source: Derbyshire health visitor data.)

1918 to April 1919) were 1.247 times (or 25 per cent) more likely to be stillborn than infants born at another time in the 1917 to 1922 period. Those born in the second wave (September 1918 to January 1919) were 1.535 times (or over 50 per cent) more likely to be stillborn. Similarly, while those born in the second or third waves were 1.326 times (or 33 per cent) more likely to die in the neonatal period, those born in early 1919 and at risk in the third wave were at highest risk, being 1.776 times (or over 75 per cent) more likely to die before reaching one month of age. Those born during 1918 were 50 per cent more likely to die between the ages of one month and one year, but the risks of post-neonatal mortality were highest for those born between July and September 1918, who were young during the second wave, still at risk during the third wave, and who were nearly twice as likely to have died.

In order to help identify the ways in which infants were at risk, be it from death from influenza itself, from some complication such as pneumonia, or via maternal health, the analyses were performed separately for different cause of death categories. ${ }^{44}$ Causes of

\footnotetext{
${ }^{44}$ Thus the risk of dying from a particular group of causes, such as congenital malformation, is assessed against the risk of not dying from that group of causes. In such analyses,
}

infants dying from causes other than that being examined are treated as censored (i.e. gone out of observation) on their death. 
1918-1919 Influenza Pandemic and Child Health

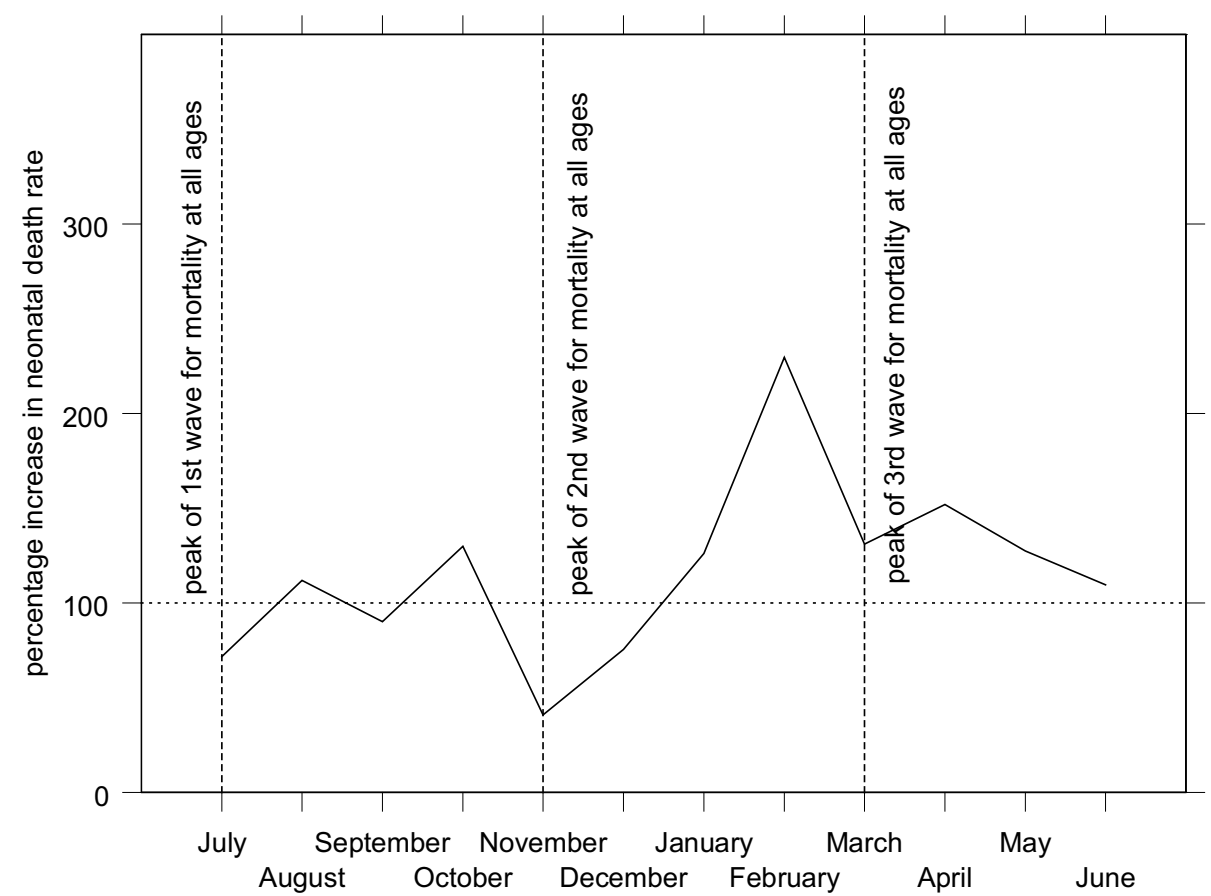

Figure 9: Indexed cohort neonatal mortality rates in Derbyshire, late 1918 and early 1919 (monthly averages for other years 1917-22=100). (Source: Derbyshire health visitor data.)

death in infancy were notoriously poorly recorded in the early twentieth century, with inaccurate, inconsistent diagnoses and a large proportion relegated to the unknown category. ${ }^{45}$ However, broad causal groupings can minimize these problems while still being instructive. The problems of cause of stillbirth reporting are potentially even greater, as such births did not have to be registered and medically certified. ${ }^{46}$ However, a reasonably high proportion of stillbirths in the data set have a cause attributed, and although some are rather speculative, many others identify recognized conditions or circumstances such as prematurity, complications of labour, congenital malformations or implicate the ill-health of the mother.

The ways in which influenza caused stillbirths will be considered first. Obviously foetuses in the womb were not at risk of catching influenza in the same way that infants

\footnotetext{
${ }^{45}$ Williams, op. cit., note 41 above, p. 68.

${ }^{46}$ Stillbirth registration was introduced in 1927 in England and Wales, and although from 1915 stillbirths were supposed to be notified under the Notification of Births (Extension) Act, it has been estimated that around a fifth to a quarter of stillbirths were not notified. It appears that the health visitor data set conforms to this pattern. See Registrar-General, The
}

Registrar-General's statistical review 1927, London, HMSO, 1929, text p. 128; E A Wrigley, 'Explaining the rise in marital fertility in England in the "long" eighteenth century', Econ. Hist. Rev., 1998, 51: 435-64, pp. 441-2; Graham Mooney, 'Stillbirths and the measurement of urban infant mortality rates', Local Popul. Stud., 1994, 53: 42-52. 


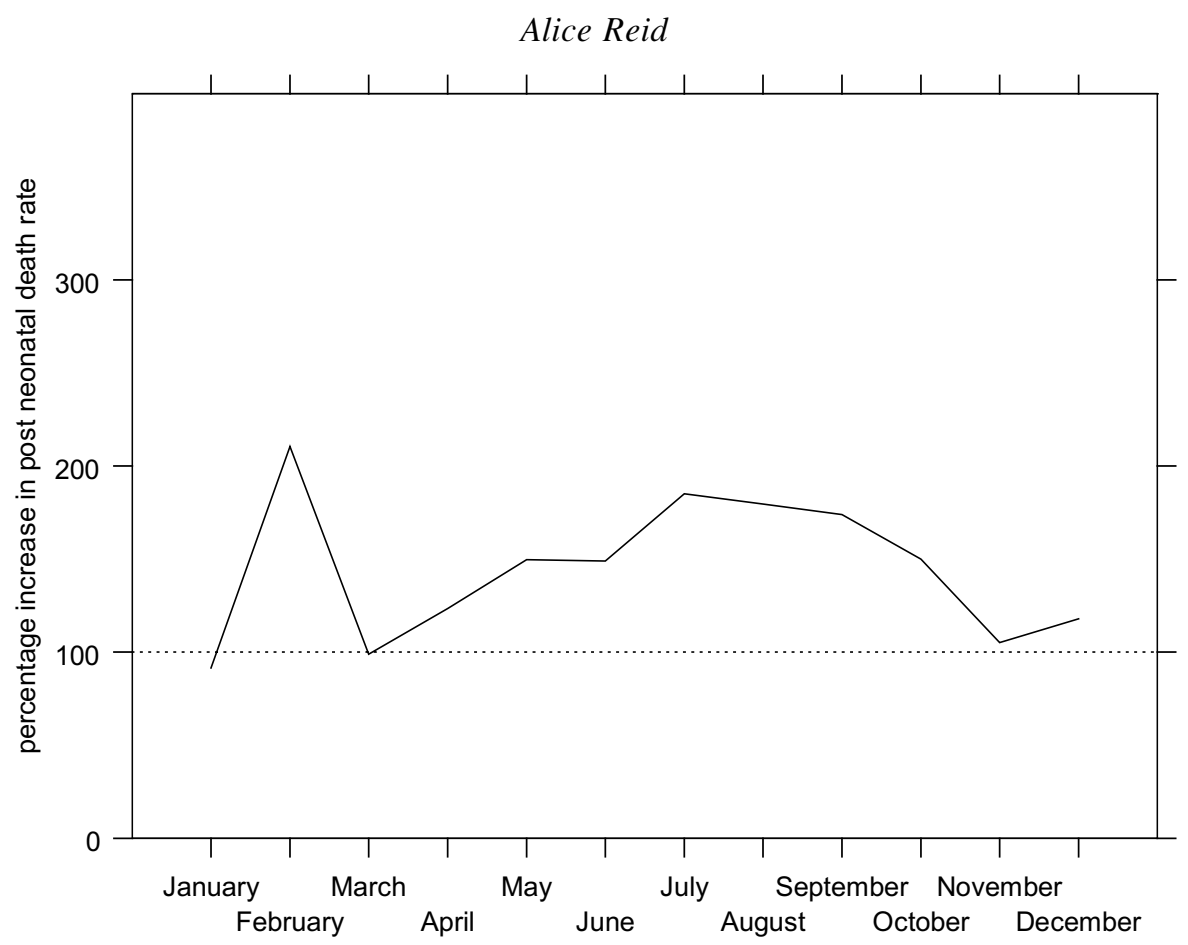

Figure 10: Indexed cohort post-neonatal mortality rates in Derbyshire, late 1918 and early 1919 (monthly averages for other years $1917-22=100$ ). (Source: Derbyshire health visitor data.)

already born were. The only way an unborn child could have been affected by the influenza virus was if its mother were afflicted. ${ }^{47}$ While comparatively few mothers were recorded as having suffered from influenza, unspecified ill-health was frequently mentioned as a cause of stillbirth, in addition to accident or shock prior to delivery and overexertion. It is reasonable to assume that during the epidemic year a large proportion of unspecified maternal illhealth would have been influenza. Figure 11, showing the proportions of all births associated with maternal ill-health for each quarter of the years 1917 to 1922, suggests that a higher proportion of stillbirths and infant deaths were attributed to maternal ill-health during the epidemic year than in the following years (the first quarter of 1917 is unusually high, and other high rates in 1917 and 1918 could be due to a build up in the influenza epidemic as suggested by Johnson ${ }^{48}$ ). However the effect was not dramatic and maternal illhealth may just have been a convenient scapegoat for an otherwise inexplicable stillbirth at any time, an effect exacerbated during the epidemic. Table 3, showing the odds ratios for stillbirths associated with periods of particular risk and different causal groups, while

\footnotetext{
${ }^{47}$ There is only one documented case of transplacental transmission of the disease although the passage of other viruses is well accepted. David H Yawn, Joella C Pyeatte, Stephan L Eichler,
}

Rafael Garcia-Bunuel, 'Transplacental transfer of
influenza virus', J. Am. med. Assoc., 1971, 216:
1022-23.
${ }^{48}$ Johnson, op. cit., note 3 above, pp. 113-22. 


\section{8-1919 Influenza Pandemic and Child Health}

\section{Table 2}

Increases in mortality connected with being born in time periods which put infants at risk during the 1918-19 influenza epidemic in Derbyshire: stillbirths, neonatal mortality and post-neonatal mortality examined separately

\begin{tabular}{llc}
\hline & Period of birth & Odds ratio $^{\mathbf{a}}$ \\
\hline Stillbirth & July 1918-April 1919 & $1.247^{*}$ \\
& Sept. 1918-Jan. 1919 & $1.535^{* * *}$ \\
Neonatal mortality & July 1918-April 1919 & $1.326^{* *}$ \\
& Jan. 1919-April 1919 & $1.776^{* * *}$ \\
Post neonatal mortality & 1918 & $1.500^{* * *}$ \\
& Feb. 1918 & $1.668^{*}$ \\
& July 1918-Sept. 1918 & $1.935^{* * *}$
\end{tabular}

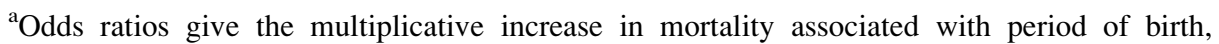
compared to a value of 1.000 for all other months in the period 1917-22. Each odds ratio is derived from a separate multivariate analysis (logistic analyses in the case of stillbirths, and hazards analyses for neonatal and post-neonatal mortality), in which other variables are also controlled (see text for details).

$* * *$ Significant at $1 \%$ level.

**Significant at $5 \%$ level.

*Significant at $10 \%$ level.

Source: Derbyshire health visitor data.

controlling for other factors, confirms the overriding importance of the health of the mother. Infants born during the third wave of the epidemic were 1.928 times (i.e. nearly twice) as likely to be stillborn due to maternal ill-health than infants born at other times.

Given that influenza may have provoked early labour or interruption of pregnancy, it is also not surprising that the risk of stillbirth due to complications of pregnancy (mainly antepartum haemorrhage, eclampsia and placenta praevia) rose during the epidemic, although the poor fit of this model warns against placing too much reliance on these figures. The risk of stillbirth due to complications of labour, however, did not rise for births during the epidemic, reflecting the more mechanical nature of such problems, which were dominated by contracted pelvis, prolapse of cord, malpresentation, and a prolonged labour. The risk of malformation with maternal rubella during pregnancy is well known, and there are also risks of abnormalities with non-specific viral illnesses, ${ }^{49}$ and some for influenza itself. ${ }^{50}$ The increased odds ratio for stillbirths due to congenital malformations, although not significant, is therefore unsurprising. The lack of significance may be attributable to their small numbers or possibly to the fact that mild abnormalities now classed under newborn encephalopathy

\footnotetext{
${ }^{49}$ Nadia Badawi, Jennifer J Kurinczuk, John M Keogh, Louisa M Alessandri, Fiona O’Sullivan, Paul R Burton, Patrick J Pemberton and Fiona J Stanley, 'Antepartum risk factors for newborn encephalopoathy: the western Australian
}

case-control study', Br. med. J., 1998, 317: $1549-53$.

${ }^{50}$ See Coffey and Jessop, op. cit., note 31 above, pp. 935-7, and MacKenzie and Houghton, op. cit., note 30 above, pp. 356-64. 


\section{Alice Reid}

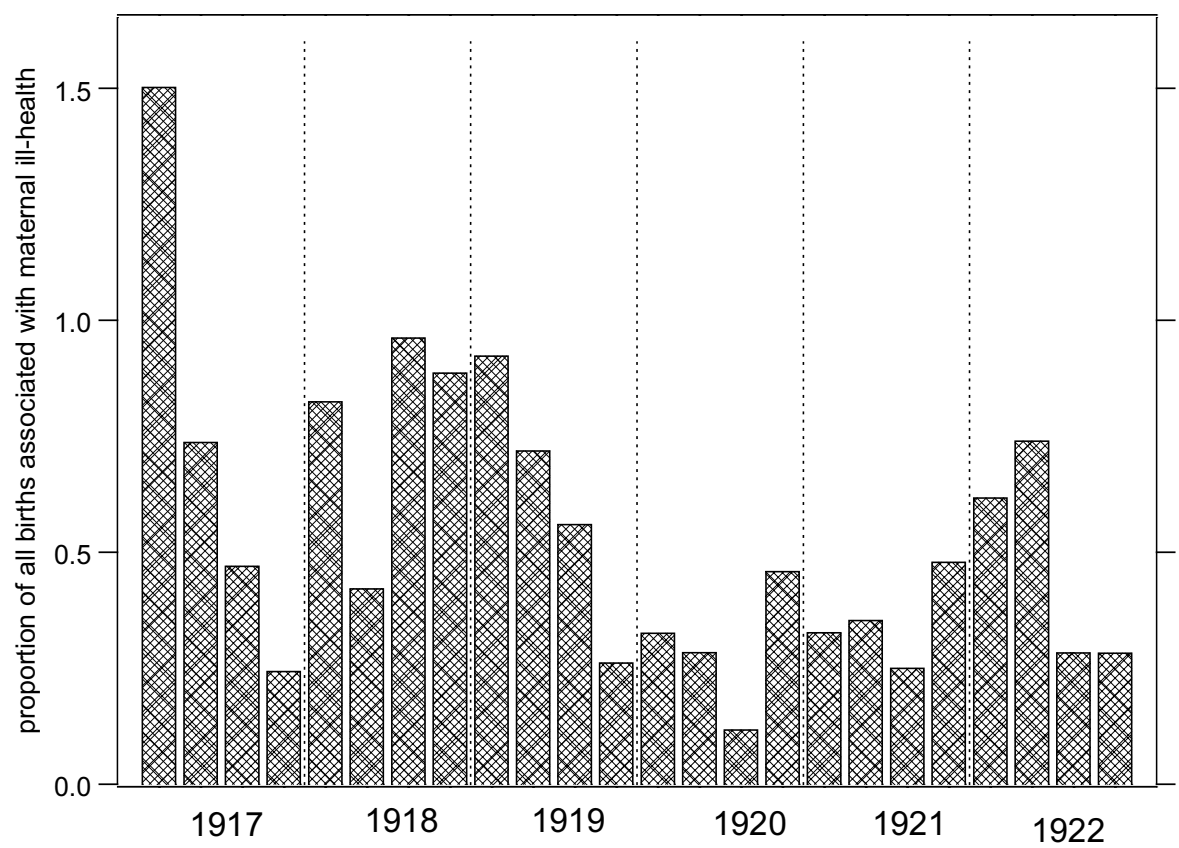

Figure 11: The proportion of all births in Derbyshire associated with maternal ill-health, by quarter, 1917-22. (Source: Derbyshire health visitor data.)

(seizures, abnormal consciousness, difficult respiration or feeding, abnormal tone or reflexes) may not have been well enough defined to be classed as congenital defects and, if there was an alternative putative reason such as the mother's health, stillbirths might have been attributed to another causal group.

Table 3 confirms that the additional risks of stillbirth during the influenza epidemic were concentrated under causes specific to the mother's health and pregnancy. Given that the route by which influenza affected the health of unborn infants was via the mother's health, and that neonatal mortality is strongly dependent on the condition of the newborn infant, it also seems plausible that the health of neonates would have been affected by maternal health. This opens the possibility that interruption of a woman's pregnancy due to influenza may have resulted not in a stillbirth but in a live premature or abnormal birth, perhaps after exposure earlier in pregnancy. ${ }^{51}$ There may therefore have been a larger pool than usual of particularly vulnerable infants at risk of neonatal death. Although such infants may not have succumbed to influenza, the epidemic can be held to have contributed to their death by making them vulnerable to other causes. Table 4 explores this possibility by showing the odds ratios associated with birth at the key periods of the epidemic for the risk of neonatal mortality from different causal groups.

\footnotetext{
${ }^{51}$ See Wynne Griffith, et al. op. cit., note 29 above.
} 


\section{8-1919 Influenza Pandemic and Child Health}

\section{Table 3}

Increases in stillbirth rates connected with being born in time periods which put infants at risk during the 1918-19 influenza epidemic in Derbyshire: different causes of stillbirth examined separately

\begin{tabular}{lcc}
\hline & \multicolumn{2}{c}{ Odds ratios associated with periods of birth } \\
\cline { 2 - 3 } & July $1918-$ April 1919 & Sept. 1918-Jan. 1919 \\
\hline All causes & $1.247^{*}$ & $1.535^{* * *}$ \\
Health of the mother & $1.782^{* * *}$ & $1.928^{* * *}$ \\
Complications of pregnancy $^{\mathrm{b}}$ & $2.165^{*}$ & $2.586^{* *}$ \\
Complications of labour $_{\text {Congenital malformations }}$ & 0.822 & 1.042 \\
Other causes & 1.092 & 1.406 \\
& 0.997 & 1.397
\end{tabular}

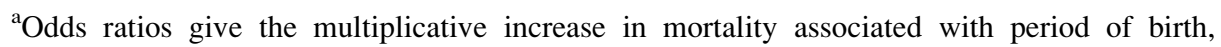
compared to a value of 1.000 for all other months in the period 1917-1922. Each odds ratio is derived from a separate multivariate logistic analysis, in which other variables are also controlled (see text for details).

${ }^{\mathrm{b}}$ The fit of this model was questionable.

$* * *$ Significant at $1 \%$ level.

$* *$ Significant at $5 \%$ level.

*Significant at $10 \%$ level.

Source: Derbyshire health visitor data.

The most striking results in the table are those which indicate the direct and associated deaths from the epidemic. The two and a half fold risk of neonatal death from the residual group (in which influenza deaths were placed) associated with birth in the third wave of the epidemic suggests that very new babies may have succumbed directly to the disease itself. Inspection of the records suggests that in a large number of these cases the mother was also afflicted. There was an almost identical risk of dying from pneumonia, an associated cause. Even though influenza was not implicated in these deaths, it is very likely that the underlying cause was indeed the 'flu and that poor certification and recording were responsible for underestimation of the effect of influenza.

In addition Table 4 shows that infants born in the third wave (January to April 1919) were 76 per cent more likely to have died from prematurity, wasting and congenital malformations than infants born at other times. This could be taken as support for the proposition that the epidemic created a larger proportion of premature births. However, the fact that viruses such as influenza are also likely to have been connected with malformations suggests another route.

Table 5 separates the prematurity, wasting and congenital malformations group into three and presents the odds ratios for birth during the epidemic for the risk of death from each subcategory. This table suggests that those born during the influenza pandemic ran no additional risk of early death from congenital malformation, and although there was an additional risk of dying from prematurity it was not significant. For those born between January and April 1919, however, the risk of dying in the neonatal period due to wasting was 


\section{Alice Reid}

Table 4

Increases in neonatal mortality connected with being born in time periods which put infants at risk during the 1918-19 influenza epidemic in Derbyshire: different causes of death examined separately

\begin{tabular}{lcc}
\hline & \multicolumn{2}{c}{ Odds ratios associated with periods of birth } \\
\cline { 2 - 3 } & July $1918-J a n . ~ 1919$ & Jan.-April 1919 \\
\hline All causes & $1.326^{* *}$ & $1.776^{* * *}$ \\
Prematurity, wasting, congenital malformation & 1.256 & $1.762^{* * *}$ \\
Bronchitis and pneumonia & 1.624 & $2.444^{*}$ \\
Complications of labour & 1.110 & 0.000 \\
Convulsions & 1.103 & 0.799 \\
Other causes (including influenza) & $1.637^{*}$ & $2.417^{* * *}$ \\
\hline
\end{tabular}

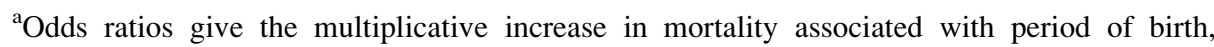
compared to a value of 1.000 for all other months in the period 1917-1922. Each odds ratio is derived from a separate multivariate hazards analysis, in which other variables are also controlled (see text for details).

$* * *$ Significant at $1 \%$ level.

**Significant at $5 \%$ level.

*Significant at $10 \%$ level.

Source: Derbyshire health visitor data.

Table 5

Increases in neonatal mortality connected with being born in time periods which put infants at risk during the 1918-19 influenza epidemic in Derbyshire: sub-categories of the prematurity, wasting and congenital malformations cause of death examined separately

\begin{tabular}{lcc}
\hline & \multicolumn{2}{c}{ Odds ratios associated with periods of birth } \\
\cline { 2 - 3 } & July $1918-$ Jan. 1919 & Jan.-April 1919 \\
\hline Prematurity & 1.048 & 1.419 \\
Congenital malformations & 0.540 & 0.767 \\
Wasting & $2.066^{* * *}$ & $2.902^{* * *}$ \\
\hline
\end{tabular}

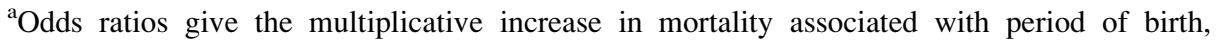
compared to a value of 1.000 for all other months in the period 1917-22. Each odds ratio is derived from a separate multivariate hazards analysis, in which other variables are also controlled (see text for details).

$* * *$ Significant at $1 \%$ level.

**Significant at $5 \%$ level.

*Significant at $10 \%$ level.

Source: Derbyshire health visitor data.

nearly three times higher than normal. This might suggest that infants who caught influenza very young died from subsequent weakness, but it is also compatible with infants disadvantaged as a result their mothers having contracted influenza. The poor recording of the causes of infant deaths has already been mentioned, and the younger the infant at death, the 


\section{8-1919 Influenza Pandemic and Child Health}

worse the problem. Prematurity was not well defined and, in the absence of the accurate estimation of gestational age, is difficult to assess. Although it was often stated in connection with stillbirths, it may not have been routinely noted for live births in the health visitors' ledgers. Infants who were born premature but who did not die immediately are likely to have had their death recorded under some other heading, even though prematurity may have contributed towards their death. The wasting category includes many causes that would be perfectly compatible with premature infants: "marasmus", "innutrition", "malnutrition", "macerated", "wasting", "weakly", “delicate", "feeble”, “debility", "inanition", "exhaustion". The lack of distinction between the causal groups, and particularly the problem with identifying premature infants, is one of the reasons for grouping into the broader category, and also suggests that it might not be legitimate to rule out a larger pool of premature weakly children as a cause of higher neonatal death during the epidemic.

Prematurity and conditions within the womb are less likely to have affected postneonatal mortality, as the most vulnerable infants might already have died during the neonatal period. Table 6 shows that indeed the excess risks for those born in 1918, and particularly for those born in February and exposed during the first and second waves, were concentrated in the risk of death from the infectious disease group, which includes influenza. The risk of dying from these causes was two and a half times greater for children born in 1918 than at any other time, and nearly six times greater for those born in February. It is interesting that although there was a 33 per cent higher chance of dying from bronchitis and pneumonia for those born during the epidemic, this was not

\section{Table 6}

Increases in post neonatal mortality connected with being born in time periods which put infants at risk during the 1918-19 influenza epidemic in Derbyshire: different causes of death examined separately

\begin{tabular}{lccc}
\hline & \multicolumn{3}{c}{ Odds ratios associated with periods of birth ${ }^{\mathrm{a}}$} \\
\cline { 2 - 4 } & Born in 1918 & Born in Feb. 1918 & Born July-Sept. 1918 \\
\hline All causes & $1.500^{* * *}$ & $1.668^{*}$ & $1.935^{* * *}$ \\
Infectious disease (incl. influenza) & $2.549^{* * *}$ & $5.815^{* * *}$ & $2.576^{* * *}$ \\
Wasting diseases & $1.946^{* * *}$ & 2.269 & $4.647^{* * *}$ \\
Bronchitis and pneumonia & 1.331 & 0.992 & 0.851 \\
Diarrhoeal diseases & 0.824 & 0.000 & 1.468 \\
Convulsions & 1.509 & 1.253 & $2.656^{* *}$ \\
Other causes & 0.995 & 0.772 & 1.192
\end{tabular}

aOdds ratios give the multiplicative increase in mortality associated with period of birth, compared to a value of 1.000 for all other months in the period 1917-1922. Each odds ratio is derived from a separate multivariate hazards analysis, in which other variables are also controlled (see text for details).

$* * *$ Significant at $1 \%$ level.

**Significant at $5 \%$ level.

*Significant at $10 \%$ level.

Source: Derbyshire health visitor data. 


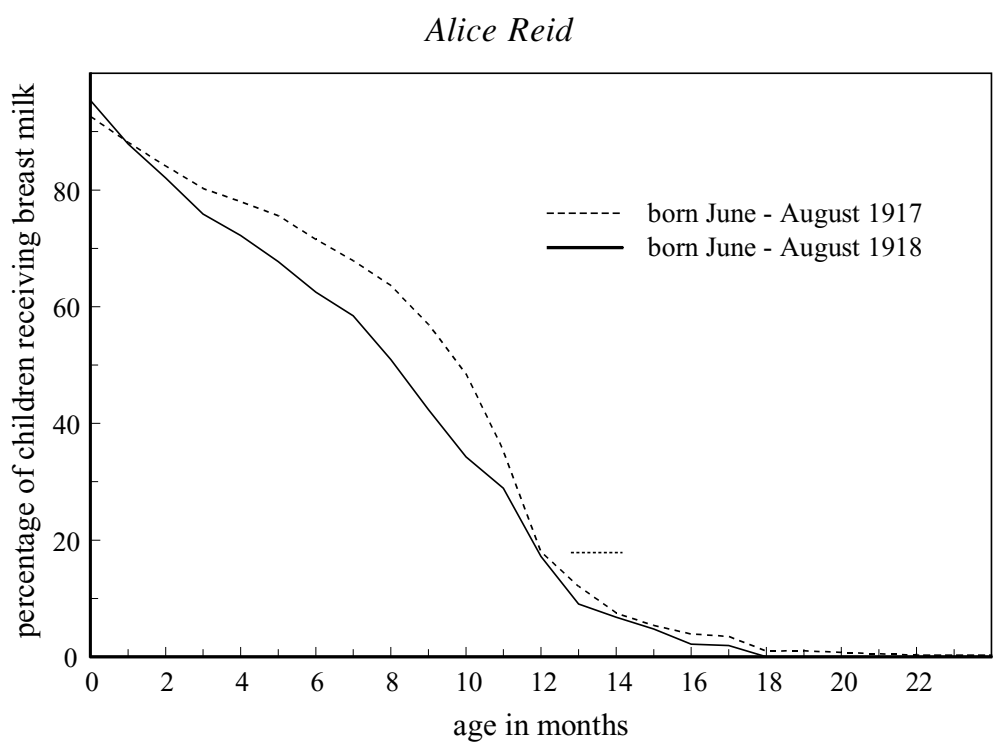

Figure 12: Percentage of infants in observation at each age who were still receiving breast milk: comparing those born in Derbyshire in the summers of 1917 and 1918. (Source: Derbyshire health visitor data.)

significant, perhaps because of small numbers, or perhaps because influenza was mentioned more often for older infants in the health visitors' ledgers. ${ }^{52}$ For infants exposed during the epidemic, the risk of dying from wasting diseases remained much higher in the post-neonatal period, nearly twice as high for those at risk during any part of the epidemic, and nearly five times as high for those born between July and September. There is a possibility that this can be accounted for by some weakly children who survived into the early post-neonatal period, but this is unlikely as, when the second month of life is excluded, the odds ratio increases to 2.191 (4.362** for those born in February and 5.140*** for those born in the summer), suggesting that older infants were more likely to die of wasting. These infants could have been weakened by the epidemic and succumbed to other causes of death later. A further possibility is that infants whose mothers had influenza were put at risk by their mother's ill health: not directly as stillbirths and possibly neonates were, but indirectly through a very sick mother's inability to feed and care for her children. Infants whose mothers have died are always at higher risk, at least partly because of the lack of breast milk, and it is plausible that mothers who were afflicted with influenza were forced to wean their infants earlier than they might otherwise have done, or that their milk supply was not as plentiful or nutritious as it would normally have been. Infants born in the summer of 1918 and still below the normal weaning age of six to nine months at the height of the second wave would have been particularly vulnerable, and therefore at increased risk of mortality from wasting diseases.

\footnotetext{
${ }^{52}$ Where more than one cause of death (such as "pneumonia following influenza") was recorded in
}

the ledgers, the antecedent cause (in this case influenza) was recorded as the primary cause. 


\section{8-1919 Influenza Pandemic and Child Health}

Figure 12 shows the percentages of infants in observation at each month whose feeding method was known, who were still being breast fed. ${ }^{53}$ The broken lines show those born between June and August 1917 and demonstrate that when they were six months old, and before the second wave of the influenza epidemic struck, over 70 per cent of children were still receiving some breast milk. The solid lines show those born in the same months a year later, who were still young and therefore most at risk of early weaning during the influenza epidemic. At six months old not much more than 60 per cent of these infants were being breastfed. There are many other influences on the duration of breast-feeding which this graph does not take into account, so although it is not conclusive, it does suggest that illhealth among mothers may have forced them to wean their infants earlier during the epidemic. The fact that nearly half the monetary value of emergency help given to 'flu victims in Manchester between 4 December 1918 and 11 January 1919 was in the form of the dried baby milk, Glaxo, lends added weight to this suggestion. ${ }^{54}$

\section{Conclusions}

One of the peculiarities of the 1918-19 influenza pandemic was the unusual age pattern of incidence and mortality, hitting the usually healthy young adults in the 20 to 40 age group most severely, in whatever part of the globe it struck. The massive relative rises in mortality in young adults and the greater potential economic impact have led to these age groups receiving the lion's share of attention in the literature. Infants and young children are traditionally a more vulnerable group, both to influenza and other forms of infectious disease, and their relative mortality was also increased dramatically, but discussion of the young is mostly relegated to mentions of school closures, or in the context of illness or death to whole families. To some extent this lack of attention can be accounted for by the lack of evidence on age-specific rates and information about the very young. The supreme dependence of the very young on their parents, particularly their mothers, however, suggests that high adult illness and mortality is likely to have an impact on infants and children, and this makes discussion of the effects on infants and children all the more interesting. While adults could be affected either directly or indirectly (via a secondary infection, a complication, or as a contributory cause), the wellbeing of infants could also be determined by their mother's health. This paper has provided support for the hypothesis that influenza infection in the first or second trimesters of pregnancy can provoke premature delivery, and therefore stillbirths or vulnerability to early death. Older infants may be disadvantaged by their ailing mother's inability to provide adequate care and nutrition, such as through breast-feeding. Of course, infants out of the womb were also at risk of catching the disease, and there was a higher risk of death from the direct effects of the 'flu itself than from the indirect effects of a mother's health, but it is very likely that the latter raised the death rate more than it would otherwise have been. In a sense, therefore, increased adult mortality contributed to increased infant mortality. If part of the increase among infants was due to the indirect

\footnotetext{
${ }^{53}$ This includes infants who were receiving both breast and artificial food. A similar graph can be drawn for those receiving only breast milk which shows the same effect.
}

\footnotetext{
${ }^{54}$ Charles Graves, Invasion by virus: can it happen again? London, Icon Books, 1969. Other help was in the form of coal, milk and food expenses.
} 


\section{Alice Reid}

effects of their mothers' illness or death, the direct effects on infants of contracting the disease themselves must be less than the overall rise in infant mortality. The relative rise in adult death rates during the epidemic is known to have been much greater than for infants, and the difference between adults and children is even greater if only the effects of suffering from the disease are considered. The virus itself therefore had an even greater proportionate effect on young adults than is revealed by the examination of overall death rates. Anthony Burgess, while undoubtedly unlucky to have lost his mother, was lucky to have escaped from both death from the influenza virus and the added health and survival disadvantages of having lost his mother. As he himself said: "I should not have been chuckling; I should have been howling for food; perhaps the visiting neighbour who had herself just been stricken had provided me with a bottle of Glaxo". 55

\footnotetext{
${ }^{55}$ Burgess, op. cit., note 1 above, p. 18.
} 